Journal of Social and Development Sciences

Vol. 1, No. 1, pp. 24-35, Feb 2011

\title{
Impact Assessment of Nutritional Supplement Program in Urban Settings: A study of under nutrition in Slum Community of Mumbai
}

\author{
Utkarsh Shah \\ Healthcare Management, Welingkar Institute of Management Studies \\ Matunga, India \\ utkarsh.shah@welingkar.org
}

\begin{abstract}
Malnutrition among 0-6 years is an impending problem, especially among economically backward communities in urban India. In an attempt to alleviate malnutrition, within the target community, the Foundation for Mother and Child, India, prepared a special food supplement, using cheap and locally available resources. A brief evaluation study was conducted to evaluate the impact of this food supplement on improvement in parameters like weight, height, and mental abilities among the participants. The study was conducted between August 2010 to October $2010(n=51)$, with the participants divided in four different age groups. The height and weight parameters were compared to ICMR standards for the age to understand the impact of the program. The mean improvement in height was $0.84 \mathrm{cms}$ (SD-0.6) while the mean improvement in weight was $0.57 \mathrm{kgs}$ (SD-0.8). A significant variance was observed due to different consumption levels of the supplement and differing levels of under-nutrition. A strong correlation was observed between the consumption level and the improvement in height and weight parameters. In addition, a positive correlation was observed between the extent of deviation from ICMR standards and levels of improvement in height and weight parameters. No differential in terms of gender was observed within the community. No significant findings were observed with reference to improvement in mental ability, primarily as the study duration was short. The study has laid the roadmap for a larger and multifaceted study to be conducted to critically evaluate the effectiveness of the nutritional supplement.
\end{abstract}

\section{Keywords: Malnutrition, Supplementary Nutrition, Anthropometric Analysis}

\section{Introduction}

As per the estimates by the World Bank (1998), India is ranked 2nd in the world with over $47 \%$ of its children exhibiting some degree of malnutrition. Malnutrition and under-nutrition tend to have a detrimental impact on the economic growth of any nation and affects the overall productivity. Further, malnutrition results in increased morbidity and mortality in the 0-6 year age group, which also tends to have an impact on the disease burden and healthcare spending in the country. Malnutrition levels across the country vary considerably with 13\% in Meghalaya and 55\% in Madhya Pradesh (Pediatric Oncall, n.d). Malnutrition is considered to be the major cause of mortality among Indians (Mitra et al, 2004). As per the census of India (2001), $17.5 \%$ of the Indian population is below the age of 6 years. The United Nations estimates that annually over 2.1 million children die before reaching the age of 5 years, largely due to preventable illness namely malaria, pneumonia, typhoid and measles. UN estimates are suggestive of over 1000 deaths in the same age group, each day, due to diarrheoal diseases. Non availability of food and micro-nutrient deficiencies is considered as the major cause of malnutrition in the Indian Context. Malnutrition is the primary cause for morbidity, due to preventable diseases and mortality among children in the developing countries (Caballero \& Maqbool, 2003). The World Bank Report on India (World Bank, 2009), has emphasized on the need to increase investments in the domain of providing micronutrients to this section of the population, in order to address to future economic growth requirements of the nation. The report has evaluated that micronutrient deficiency, if not addressed adequately at this juncture, may cost India US $\$ 2.5$ billion annually.

There is a significant urban and rural divide with regards to the prevalence of under nutrition in India. Under nutrition in rural children is about $50 \%$ while $38 \%$ of urban children suffer from under nutrition (World Bank, 2009). Similarly the incidence of under nutrition is higher in females compared to males, largely attributed to the social and cultural attitude towards a female child. Socially backward sections tend to suffer from under nutrition more than the other sections of the society. Clinical evidence reiterates the role of 
malnutrition in increased susceptibility to infections, which attributes to high morbidity and mortality among children below the age of five years. Malnutrition affects epithelial and mucosal integrity, immunoglobulin synthesis, lymphocyte differentiation; etc will contribute to impairment in immune functions and recurrent infections (Chandra \& Kumari, 1994). Rapid change in population dynamics coupled with changing economic scenario has had considerable impact of life style patterns. India is presently faced with dual burden of rising incidence of obesity on one hand and consistently increasing malnutrition levels on the other. It is critical to realize that obesity or overweight children may also suffer from micronutrient deficiencies due to faulty dietary practices (Pediatric Oncall, n.d). There is an impending need to address to the issue of malnutrition and micro-nutrient deficiency, as these are directly related to educational attainment, labor productivity and economic growth of a child which has direct implications of financial health of the entire nation (World Bank, 2009). The objectives of the study are

1. To review the levels of under nutrition in the target community based on ICMR standards using anthropometric data

2. To understand the impact of the intervention on improvement in anthropometric parameters in the target community

3. To comprehend the linkage between consumption of the nutria-cookie and improvement in anthropometric parameters in the target community

4. To ascertain the strategy for subsequent course of action to improve overall health of the target community.

\section{The Supplementary Nutrition Program: Rationale}

Lack of adequate quantity of balanced food has been considered to be one of the primary reasons for malnutrition in the developing world (Caballero \& Maqbool, 2003). Further, studies have been indicative of a strong association between childhood morbidity and mortality with malnutrition (Fawzi, et al, 1997). This in turn has a detrimental impact on the overall growth and development of the child (Pelletier, Frongillo \& Habicht, 1993), which limits the ability of the child to realize their full potential in life. Further lack of knowledge, especially regarding breast feeding and weaning practices have also been responsible for increased incidence of malnutrition, especially in the neonatal and infant populations (Solomon \& Zemene, 2008). As per the estimates, malnutrition levels in the country continue to remain as high as $45 \%$ in the $0-3$ year age group (NFHS, 2006) and there is concurrent evidence of increase in malnutrition in some regions. Though there are several factors which contribute to malnutrition and under nutrition, in order to address to the underlying cause of inadequate food, UNICEF in collaboration with the Government of India initiated the ICDS program (UNICEF India, n.d). Analysis and findings of the intervention suggested that the 'supplementary nutrition program' under the ICDS is a low cost and effective technique to combat malnutrition in the country (UNICEF India, n.d).

Though the ICDS program is the largest nutrition supplementation program in the world, its impact on improving the health status and nutritional levels of the target group has been highly constrained. Amidst a wide range of factors, poor implementation strategies have been primarily responsible for this failure (UNICEF India, n.d). As per estimates, the ICDS program has been limited to $33 \%$ of the total eligible population, with merely $26 \%$ receiving supplementary food (Mittal, n.d). Further small scales studies being conducted various localities in urban India (Hasan, 2010); high rates of malnutrition continue to plague the Indian population. Further, malnutrition if not identified and treated early, can impact the growth and health of the individual (Shashidhar \& Grigsby. 2009) and often a late intervention limits the ability of the child to recover completely from the deviation (Lien, Mayer \& Winick, 1997). In lieu of these facts, the FMCHI (a small regional NGO working with slum community in Mumbai), initiated a Supplementary Nutrition Program. The program aimed at addressing protein energy malnutrition along with micronutrient deficiency among the target beneficiaries (i.e. 0-6 years). In order to minimize the issues related to providing cooked food, the Supplementary Nutrition Program of the FMCHI, provided the beneficiaries with pre-cooked nutria-cookie, which was aimed at supplementing the energy and nutrient requirement of the beneficiaries. The ingredients and nutritive values of the ingredients of the Nutri-cookies were meticulously computed to address to the key issue of under nutrition and micronutrient deficiency. The table below gives a brief understanding of the details of the product. 
Table1: Ingredients of a Nutri-Cookie

\begin{tabular}{lll}
\hline S.No & Ingredients & Quantity per 40 grams of Nutri-cookie \\
\hline 1 & Groundnut & $9.22 \mathrm{~g}$ \\
2 & Almond & $1.85 \mathrm{~g}$ \\
3 & White Til & $1.85 \mathrm{~g}$ \\
4 & Flaxseed & $2.7 \mathrm{~g}$ \\
5 & Dried Dates & $4.6 \mathrm{~g}$ \\
6 & Milk Powder & $1.85 \mathrm{~g}$ \\
7 & Watermelon Seeds & $1.85 \mathrm{~g}$ \\
8 & Jaggery & $14.8 \mathrm{~g}$ \\
9 & Sugar & $3.7 \mathrm{~g}$ \\
10 & Cocoa Powder & $1.38 \mathrm{~g}$ \\
11 & Ghee & $1.85 \mathrm{~g}$ \\
12 & Khaskhas & $0.46 \mathrm{~g}$ \\
13 & Cornflakes & $0.9 \mathrm{~g}$ \\
\hline
\end{tabular}

The nutria-cookie was prepared from cheaply available local food ingredients, to compliment the daily dietary intake of the beneficiaries. In order to review the effectiveness of the program and the specially designed Nutri-cookies, a comprehensive evaluation study was conducted.

\section{The Methodology of Implementation}

After pilot testing of the Nutri-cookies for their acceptability with regards to of taste, quality, texture, satiety, appearance, etc, the intervention study was conducted. Though the intervention aimed at including pregnant and lactating mothers, due to their limited numbers, they were excluded from the evaluation study. The evaluation study was designed to focus on children between the age group of 2-6 years.

All the beneficiaries were identified and enrolled into the Supplementary Nutrition Program. The program span over three months from August 2010 to October 2010, during which the enrolled beneficiaries were supplied with one Nutri-cookie each day (except Sundays). Prior to initiating the program, the enrolled beneficiaries were clinically evaluated by the Pediatrician with regards to overall health status and the team recorded essential Anthropometric parameters (namely weight and height). Anthropometric parameters were primarily used to evaluate the effectiveness of the intervention, as anthropometry is considered as a sensitive indicator for growth, health and development of children (WHO, 1995). Linear Correlation Analysis has been used to analyze and interpret the findings of the study.

\section{Findings of the Study}

\section{Age Profile of the Study Sample}

The study began with 45 Balwadi Children in the age group of 0-6 years and 15 children in the age group of 06 years, who were not a part of the Balwadi. However, due to several reasons, dropouts were observed during the study duration. The sample size and distribution of the beneficiaries was altered slightly. Only about 41 Balwadi children and 10 children from outside Balwadi were evaluated for the intervention. The distribution of these children as per their age group is provided in the Figure.1 below. 
Figure.1. Distribution of the Sample according to the Age

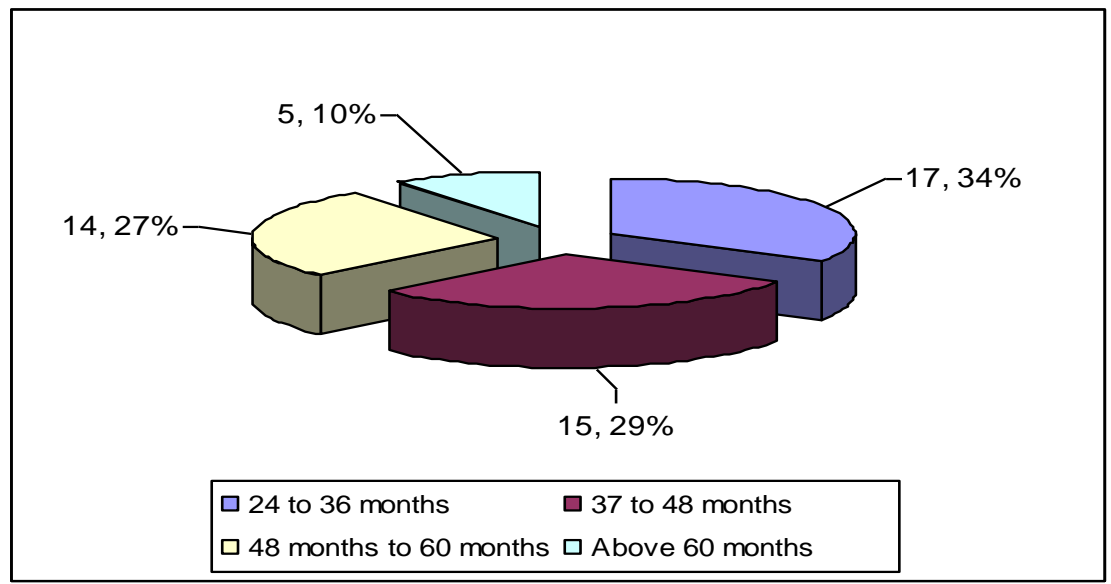

The average age along with the standard deviation for each of the age groups has been provided in the table 2 below:

Table2: Average Age in each group

\begin{tabular}{lll}
\hline Age Group & Mean Age (in months) & Standard Deviation (in months) \\
\hline 24-36 months & 32.35 & 2.21 \\
37-48 months & 43.13 & 3.66 \\
49-60 months & 54.1 & 3.67 \\
Above 60 months & 66.4 & 6.98 \\
\hline
\end{tabular}

The above table, with standard deviation, is indicative of limited variance within each of the defined groups, except the age group of above 60 months, which showed high degree of variance. In general, the limited variance, allowed the internal comparison of the groups, with a high degree of confidence.

\section{Pre-Intervention Profile of the Study Sample: Weight and Height}

The Anthropometric parameters (namely weight and height) of the participants were measured prior to the starting the intervention. The detailed profile of the beneficiaries is tabulated in Table. 3 below along with its variation from ICMR, 1990 guidelines,

Table3: Detailed Weight and Height Profile of the Sample prior to the intervention

\begin{tabular}{lllll}
\hline Age Group & $\begin{array}{l}\text { Mean Height ( SD- } \\
\text { H) in centimeters }\end{array}$ & $\begin{array}{l}\text { Mean Weight } \\
\text { W) in kilograms }\end{array}$ & $\begin{array}{l}\text { \% deviation from ICMR Standards } \\
\text { (Mean of Individual variations) }\end{array}$ \\
\hline & & & $\begin{array}{l}\text { Height } \\
(\%)\end{array}$ & Weight (\%) \\
& & & -6 & -18.8 \\
24-36 months & $87.03(4.03)$ & $11.29(1.09)$ & -7.7 & -20.4 \\
37-48 months & $91.77(4.48)$ & $12.29(1.42)$ & -6.3 & -23.4 \\
49-60 months & $98.89(4.77)$ & $13.16(1.34)$ & -12.6 & -33.7 \\
Above 60 months & $97.5(2.35)$ & $12.44(1.42)$ & & \\
\hline
\end{tabular}


The study sample had lower mean weights and heights, compared to the ICMR standards, indicating rampant under-nutrition, within the slum community. Further, it was observed that with increasing age, the mean negative deviation from ICMR standards also increased dramatically. This could be attributed to the fact that, nutritional insults at a young age, tend to have detrimental effect on the overall health even as the children grows older (Shashidhar \& Grigsby, 2009) and often malnourished children fail to recover completely from the negative deviation (Lien, Mayer \& Winick, 1997). Figure. 2 shows a strong positive correlation between increasing age and increasing mean deviation from ICMR standards, which reiterates that if under nutrition is not adequately addressed at an early age, it tends to worsen and impacts the overall performance of the child.

\section{Figure.2. Mean Anthropometric Deviation from ICMR standards as per Age Groups}

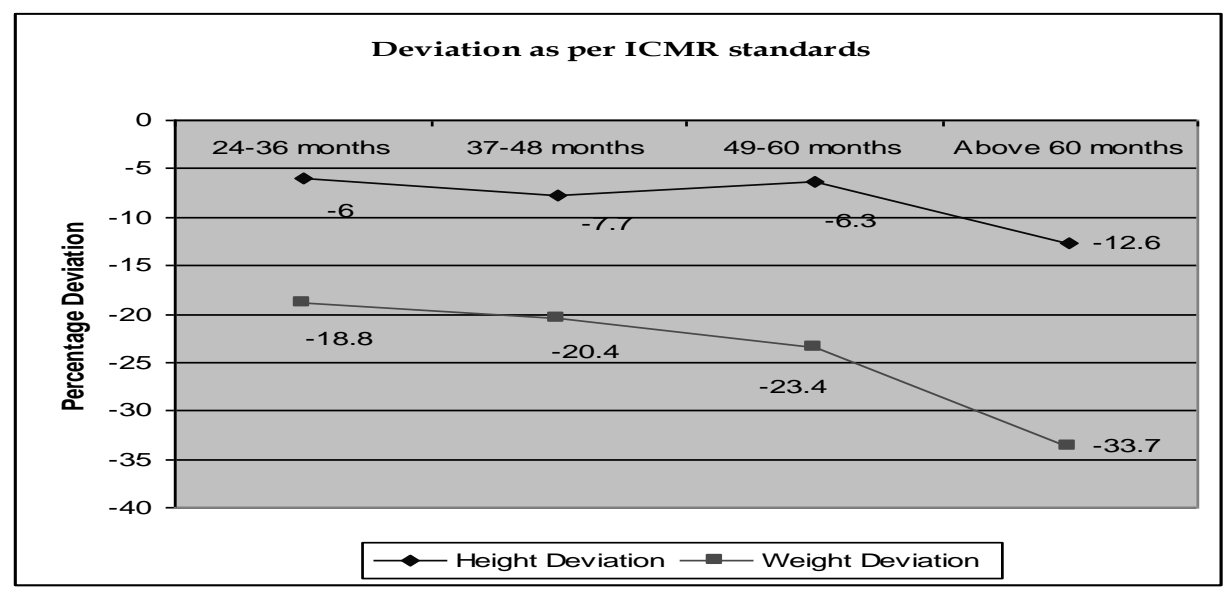

Except for four participants, who showed height at par or better than ICMR standards for their age, all the participants showed weight below ICMR standards. This clearly rationalizes the selection of the participants for this proposed intervention. The objective of this intervention was to improve the anthropometric dimensions of the participants, so that they are at par with ICMR standards for their age.

\section{Intervention Assessment}

\section{General Assessment: Mean Improvement in Weight}

After providing the supplements to the beneficiaries of the program, considerable change in anthropometric parameters was observed. The table. 3 summarizes details of three variables (mean percentage deviation from ICMR standards, mean percentage improvement, and mean consumption of nutri-cookie by each group) in comparison to the mean initial weight of the participants (irrespective of their age).

Table 4: Initial Weight of the participants in comparison with the average improvement

\begin{tabular}{llll}
\hline $\begin{array}{l}\text { Mean Initial } \\
\text { Weight }\end{array}$ & $\begin{array}{l}\text { Mean percentage } \\
\text { deviation } \\
\text { ICMR standards }\end{array}$ & $\begin{array}{l}\text { Mean } \\
\text { improvement in weight after } \\
\text { the intervention }\end{array}$ & $\begin{array}{l}\text { Mean } \\
\text { consumption of } \\
\text { cookies (grms) }\end{array}$ \\
\hline $\begin{array}{l}\text { Less than or } \\
\text { equal to } 10 \mathrm{kgs}\end{array}$ & $-26.39 \%$ & $1.66 \%$ & 968 \\
$10.1 \mathrm{~kg}-11 \mathrm{~kg}$ & $-32.71 \%$ & $5.65 \%$ & 1192 \\
$11.1 \mathrm{~kg}-12 \mathrm{~kg}$ & $-23.88 \%$ & $7.32 \%$ & 1156.9 \\
$12.1 \mathrm{Kg}-13 \mathrm{Kg}$ & $-20.13 \%$ & $2.88 \%$ & 1272.5 \\
$13.1 \mathrm{~kg}-14 \mathrm{~kg}$ & $-18.49 \%$ & $5.39 \%$ & 1529 \\
Above $14 \mathrm{~kg}$ & $-14.90 \%$ & $3.26 \%$ & 1873.3 \\
\hline
\end{tabular}


Figure 3: Diagram depicting the correlation between average deviation from ICMR standards and average improvement (Weight)

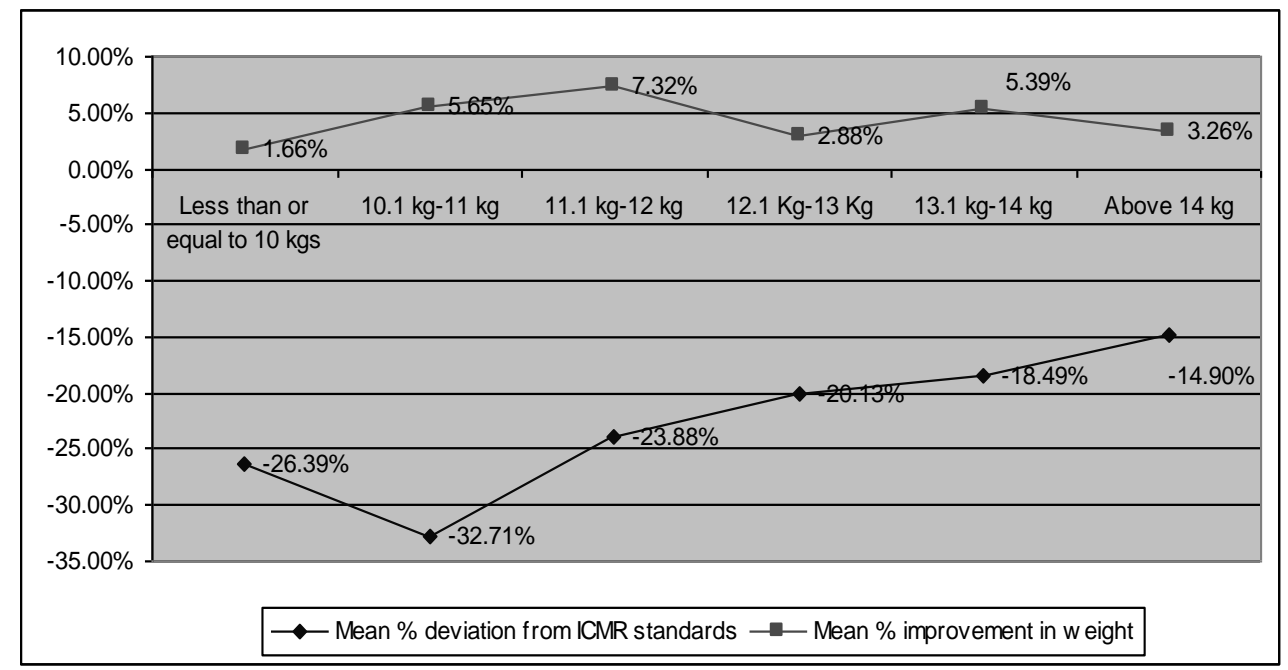

Using simple linear correlation technique (Pearson technique), it can be deduced that there was no correlation between the initial weight of the child and improvement in weight gain. However, there seemed to be a weak positive correlation between mean deviation from ICMR standards and improvement in weight of the child. Greater the deviation from ICMR standards more was the improvement in weight observed. This has been found to be consistent with other studies (Alves et al, 2010), which analyzed using multivariate analysis, that incremental improvement in weight was related to the deviation from the Z-score standards.

\section{General Assessment: Mean Improvement in Height}

In reference to change in height a slightly different observation was made. Using simple linear correlation technique (Pearson technique), a relationship was observed between the mean initial height and mean improvement in height. No relation was observed between mean deviation from ICMR standards and improvement in height. The figure below depicts the correlation using linear correlation.

\section{Figure 4: Diagram depicting the correlation between average deviation from ICMR standards and} average improvement (Height)

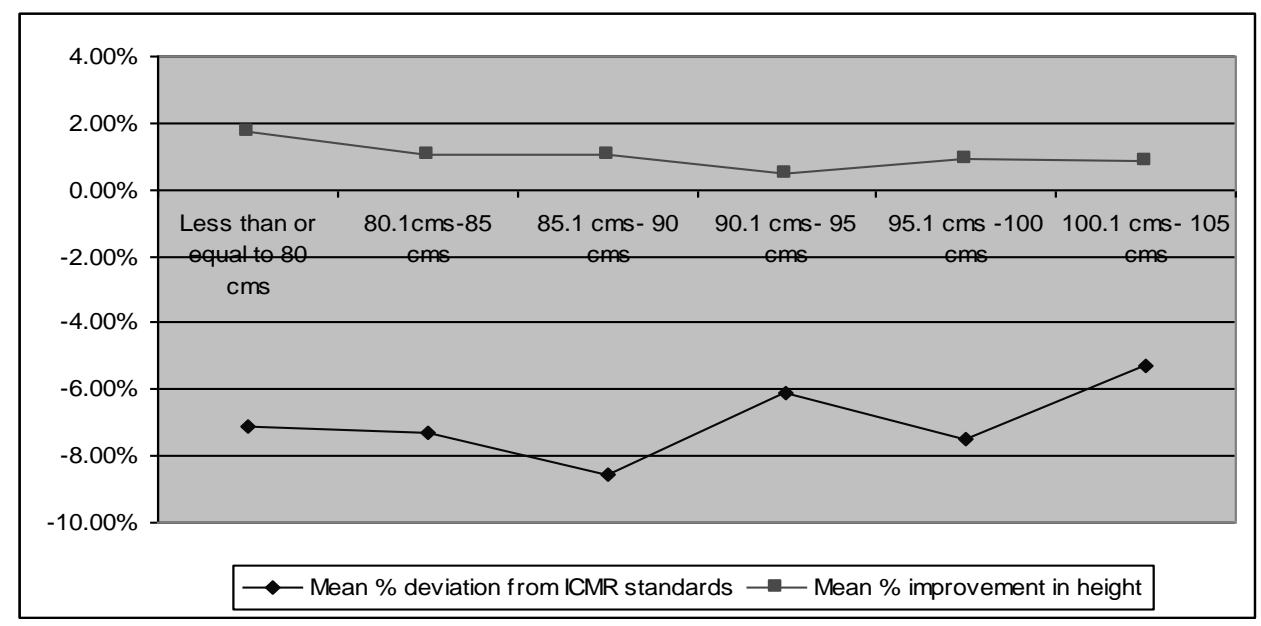


Table 5 depicts the percentage deviation of height from ICMR standards and the average improvement in percentage.

Table5: Initial Height of the participants in comparison with the average improvement

\begin{tabular}{lll}
\hline Mean Initial Height & $\begin{array}{l}\text { Mean percentage deviation } \\
\text { from ICMR standards }\end{array}$ & $\begin{array}{l}\text { Mean percentage improvement in } \\
\text { height after the intervention }\end{array}$ \\
\hline Less than or equal to $80 \mathrm{cms}$ & $-7.10 \%$ & $1.77 \%$ \\
$80.1 \mathrm{cms}-85 \mathrm{cms}$ & $-7.30 \%$ & $1.08 \%$ \\
$85.1 \mathrm{cms}-90 \mathrm{cms}$ & $-8.54 \%$ & $1.05 \%$ \\
$90.1 \mathrm{cms}-95 \mathrm{cms}$ & $-6.11 \%$ & $0.51 \%$ \\
$95.1 \mathrm{cms}-100 \mathrm{cms}$ & $-7.51 \%$ & $0.94 \%$ \\
$100.1 \mathrm{cms}-105 \mathrm{cms}$ & $-5.29 \%$ & $0.88 \%$ \\
\hline
\end{tabular}

\section{General Assessment: Weight and Height in Reference to consumption of the Nutri-cookie}

On the other hand, a strong correlation was observed between the consumption of Nutri-cookies and the percentage improvement in weight (though no relation was observed with respect to percentage improvement in height). The Table 6 below the brief details as per consumption of the Nutri-cookies.

Table6: Cumulative intake of Nutri-cookies and percentage improvement in weight and height

\begin{tabular}{lll}
\hline Cumulative Intake of Nutri-cookies & $\begin{array}{c}\text { Percentage } \\
\text { improvement in Weight }\end{array}$ & $\begin{array}{c}\text { Percentage } \\
\text { Improvement in Height }\end{array}$ \\
\hline$>1999$ grams of supplement & $6.13 \%$ & $0.82 \%$ \\
1500-1999 grams of supplement & $4.11 \%$ & $0.78 \%$ \\
1000 -1499 grams of supplement & $4.06 \%$ & $1.14 \%$ \\
$<999$ grams of supplement & $5.19 \%$ & $0.74 \%$ \\
\hline
\end{tabular}

The figure 5 below provides a graphical representation of the data. It is indicative that the beneficiaries were observed to have significant weight gain, as their consumption of the Nutri-cookies increased. Though the liner correlation group showed a two tail improvement, the weight gain improvement in the group consuming less than 999 grams of the supplement, was skewed due to a single participant2. After excluding this skewed finding, the average improvement in weight was noted at $3.01 \%$ for beneficiaries consuming less than 999 grams of the supplement. This clearly indicated a strong positive correlation between consumption and improvement in weight. With regards to improvement in height, no significant findings were observed. 
Figure.5.The correlation between cumulative consumption of Nutri-cookies and improvement in weight and height

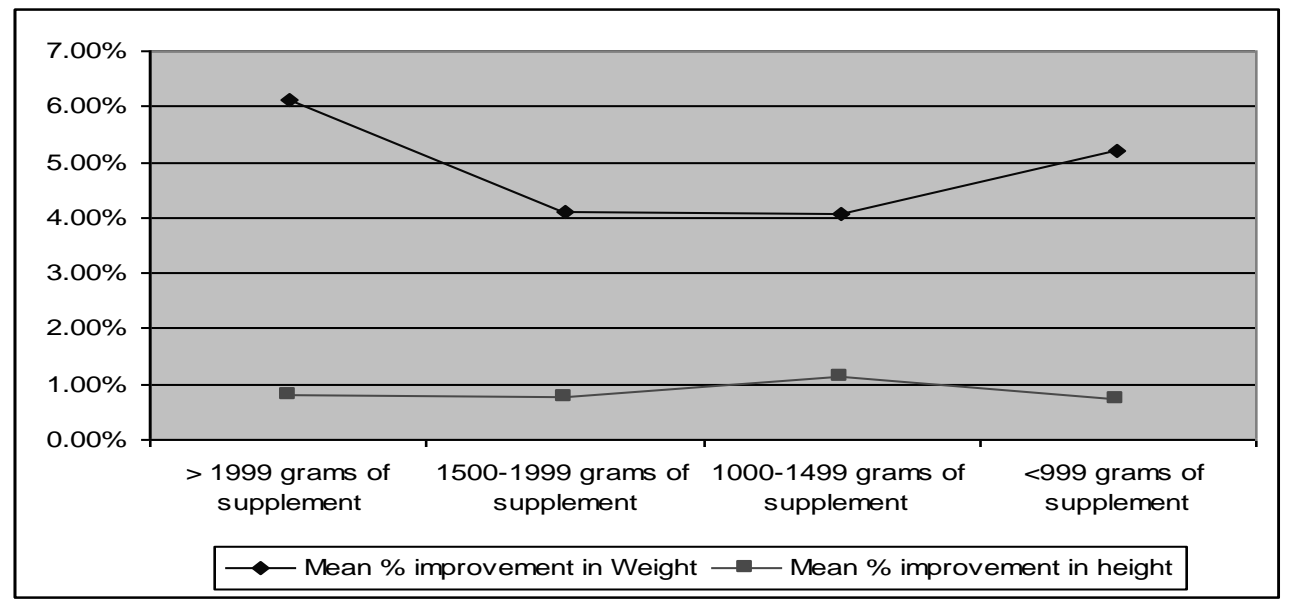

\section{Gender Specific Mean Improvement}

On comparing the findings as per gender of the participant the key modalities observed have been depicted in the Table 7 below:

Table7: Key difference as per the gender of the participant

\begin{tabular}{|c|c|c|c|c|c|c|}
\hline \multirow[t]{3}{*}{ Gender } & \multirow[t]{3}{*}{ Number } & \multirow{3}{*}{$\begin{array}{l}\text { Mean \% } \\
\text { deviation from } \\
\text { ICMR } \\
\text { standards } \\
\text { (Weight) }\end{array}$} & \multirow{2}{*}{$\begin{array}{ll}\text { Mean } & \% \\
\text { deviation } & \end{array}$} & \multirow{2}{*}{$\begin{array}{l}\text { Mean \% } \\
\text { improvem }\end{array}$} & \multirow{3}{*}{$\begin{array}{l}\text { Mean\% } \\
\text { improvement } \\
\text { in Height }\end{array}$} & \multirow{3}{*}{ 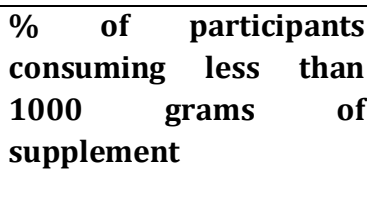 } \\
\hline & & & & & & \\
\hline & & & $\begin{array}{l}\text { from ICMR } \\
\text { standards } \\
\text { (Height) }\end{array}$ & $\begin{array}{l}\text { ent in } \\
\text { weight }\end{array}$ & & \\
\hline Female & 29 & $-20.97 \%$ & $-7.11 \%$ & $4.16 \%$ & $0.93 \%$ & $17.24 \%$ \\
\hline Male & 22 & $-23.35 \%$ & $-7.09 \%$ & $5.41 \%$ & $0.89 \%$ & $31.82 \%$ \\
\hline
\end{tabular}

The findings suggest that there was no significant difference in the weight and height parameters of male and female participants prior to the intervention. However it is worthwhile to note that over $31 \%$ of male participants consumed less than 1000 grams of supplements compared to their female counterparts (17.24\%). It is worthwhile to note that the deviation of male participants from ICMR standards was higher than their female counterparts and apparently, they showed higher mean improvement in weight, reiterating the relationship between extent of negative deviation from ICMR standards and mean improvement in weight.

Figure 6: Mean improvement in Males $(n=22)$ and Females $(n=29)$

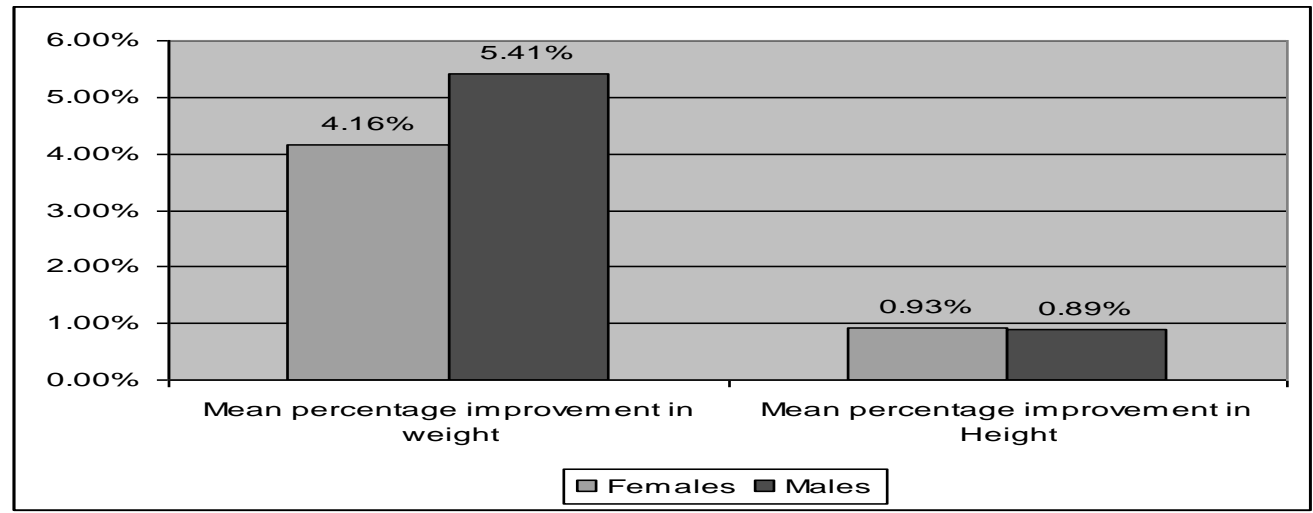




\section{Internal Comparison within Each Age-Group: Gender wise comparison}

An internal comparison is essential to verify the findings observed at a general level.

\section{Age Group: 24 months to 36 months}

On internal comparison of the beneficiaries between the age group of 24 months to 36 months, some of the key observations have been tabulated in the Table. 8 below.

Table8: Gender-wise differential of Weight and Height gain in 24-36 months age group

\begin{tabular}{llll}
\hline Particulars & $\begin{array}{l}\text { Mean improvement in } \\
\text { Weight (SD) }\end{array}$ & $\begin{array}{l}\text { Mean improvement } \\
\text { in Height (SD) }\end{array}$ & $\begin{array}{l}\text { Mean } \\
\text { consumption of supplement }\end{array}$ \\
\hline Group & $0.35 \mathrm{kgs}(0.37)$ & $1 \mathrm{cms} \mathrm{(0.85)}$ & 987.65 Nutri-cookies $(201.35)$ \\
Females & $0.45 \mathrm{kgs}(0.27)$ & $1.26 \mathrm{cms}(1.01)$ & 1095 Nutri-cookies \\
Males & $0.26 \mathrm{kgs}(0.43)$ & $0.77 \mathrm{cms} \mathrm{(0.66)}$ & 892.2 Nutri-cookies \\
\hline
\end{tabular}

The internal comparison between the beneficiaries of the age group I clearly reiterate the general findings of the study. There is a direct positive correlation between gain in weight and height to the consumption of nutri-cookies. It is worthwhile to note that with regards to weight gain in the male beneficiaries of the group, significant variance was observed which was attributed to extremes in weight gain and weight loss in this sub-group3.

\section{Age Group: 37 months to 48 months}

On internal comparison of the beneficiaries between the age group of 36 months to 48 months, some of the key observations have been tabulated in the Table 9 below.

Table9: Gender-wise differential of Weight and Height gain in 36-48 months age group

\begin{tabular}{llll}
\hline Particulars & $\begin{array}{l}\text { Mean improvement } \\
\text { in Weight (SD) }\end{array}$ & $\begin{array}{l}\text { Mean improvement } \\
\text { Height (SD) }\end{array}$ & $\begin{array}{l}\text { inean } \\
\text { consumption of supplement }\end{array}$ \\
\hline Group & $0.24 \mathrm{~kg}(0.46)$ & $0.66 \mathrm{cms}(0.49)$ & 1404.67 Nutri-cookies \\
Females & $0.23 \mathrm{~kg}(0.43)$ & $0.54 \mathrm{cms}(0.36)$ & 1329 Nutri-cookies \\
Males & $0.28 \mathrm{~kg}(0.56)$ & $0.9 \mathrm{cms}(0.65)$ & 1556 Nutri-cookies
\end{tabular}

General analysis reinstates the findings of increase in weight and height directly proportional to the cumulative consumption of the Nutri-cookies. It is worthwhile to note that there is a significant variance observed in this subgroup with regards to weight and height gains. Four female beneficiaries while one male beneficiary in this subgroup recorded weight loss. On re-evaluation of the medical profile of these beneficiaries it was observed that some of them suffered from acute debilitating conditions4, which could be attributed as the cause for weight loss. Consistent increase in height however indicated that the nutria-cookie was beneficial even during their illness.

\section{Age Group: 49 months to 60 months}

On internal comparison of the beneficiaries between the age group of 49 months to 60 months, some of the key observations have been tabulated in the Table 10 below. 
Table10: Gender-wise differential of Weight and Height gain in 49-60 months age group

\begin{tabular}{llll}
\hline Particulars & $\begin{array}{l}\text { Mean improvement } \\
\text { in Weight (SD) }\end{array}$ & $\begin{array}{l}\text { Mean improvement in } \\
\text { Height (SD) }\end{array}$ & $\begin{array}{l}\text { Mean } \\
\text { consumption of supplement }\end{array}$ \\
\hline Group & $0.1 .06 \mathrm{~kg}(1)$ & $0.73 \mathrm{cms}(0.47)$ & $\begin{array}{c}\text { cumulative } \\
\text { Males }\end{array}$ \\
Females & $1.1 \mathrm{~kg}(1.34)$ & $0.75 \mathrm{cms}(0.52)$ & 1732.86 Nutri-cookies $(450.4)$ \\
& $1.03 \mathrm{~kg}(0.76)$ & $0.71 \mathrm{cms}(0.46)$ & 1695 Nutri-cookies \\
\hline
\end{tabular}

Comparison of the segregated findings of group III also indicate that the improvement in weight and height have been linked to the consumption of the Nutri-cookie. It is worthwhile to note that a high variance is observed in the male subgroup of this age group. This variance is attributed to a single observation in which participant B1 recorded a weight gain of $3.8 \mathrm{kgs}$ (approximately $33.04 \%$ of his initial weight). None of the participants recorded weight loss during the tenure of the intervention.

\section{Age Group: Above 60 months}

Since the number of beneficiaries in Group IV was very low an internal comparison was not done as it would yield skewed results. Excepting participant OB25, all participants exhibited weight gain. No significant findings were observed in this age group.

\section{Impact on Metal Alertness and Cognition}

An effort was made to evaluate the impact on metal agility and cognition among the beneficiaries participating in the intervention. All the beneficiaries were exposed to a 10 -item recognition test at the beginning of the intervention and their mental alertness and cognitive skills were recorded. The same test was repeated on the completion of the intervention to review the improvement. The findings were inconclusive. Though no deterioration was observed among the beneficiaries with regards to their mental functions, the study duration was too short to provide conclusive evidence on the effect of the nutria-cookie on enhancement of mental functions.

\section{Discussion and Conclusion}

The participants selected for the study had similar cultural, religious, and socio-economic strata, which eliminated the possibility of attributing the changes observed after the intervention to these confounding variables. However there were certain variables which affected the findings of the study which included illness especially of the severe form, health seeking behavior of the parents, irregular intake of the supplements, etc. An effort was made to address to these variations and interpret their impact on the overall contribution in terms of reducing under nutrition among the beneficiaries. In the community setting, it was observed that with the severity of under-nutrition increased with advancing age, if not managed at an early age. This reiterated the importance of an intervention targeting the younger age group between 0-6 years, to improve overall health status and reduce susceptibility of infections and illnesses.

The assessment of the findings indicated that there was a strong association between the consumption of nutria-cookie designed by the FMCHI team and increase in weight and height among the beneficiaries. This finding was consistent at a general level and also when internal comparison was made between specific age groups. Excepting a few participants, in whom weight loss was recorded and attributed to some form of underlying illness, a consistent improvement in height and weight parameters was observed among the beneficiaries. This was indicative of the effectiveness of the nutria-cookie in improve general health among underweight children. Further, higher consumption of the nutria-cookie should higher positive gains in terms of improvement in height and weight. In addition, the findings of the study suggested that the benefits of the Nutri-cookie were positively correlated with the extent of malnourishment among the beneficiaries. Higher gains were observed in beneficiaries who were grossly underweight, in comparison to ICMR standards. This implies that the Nutri-cookies were beneficial in providing essential nutrients, carbohydrates, and vitamins to 
the child to help reduce the deficit. The benefits of the Nutri-cookies (in terms of improving height and weight) reduced as the deviation from ICMR standards reduced, which over-rules the possibility of obesity among children with higher levels of consumption of the nutri-cookie. Though the beneficiaries were evaluated for mental performance, the findings of this evaluation were inconclusive primarily due to short duration of the intervention. Further no gender difference was observed in terms of the consumption or the benefits from the intervention. The Nutri-cookie designed by FMCHI, has shown promising results in the domain of improving malnutrition and under nutrition among children. This evaluation study calls for implementation of the program on a larger scale to further assess and review the impact of the program on under nourished children between the age group of 0-6 years.

\section{Limitations of the Study}

1. Not all the enrolled beneficiaries participated in this intervention program. Several drop-outs were recorded during the course of the intervention. In order to minimize errors, only those beneficiaries participating for the entire length of the program were considered for final evaluation. However, due to ethical reasons, some late entries were allowed; however, these were not considered for the final analysis.

2. The consumption of the nutria-cookie was not uniform. There was a considerable amount of variation in terms of the frequency and quantity of consumption. Further, problems including occasional unwillingness of the beneficiaries to consume the nutritional supplement, unavailability, and absentees in the pre-school, cultural, and religious constraints (like fasting), etc limited standardized consumption patterns. In order to minimize the errors, evaluation was based on cumulative consumption of the nutri-cookie.

3. The program was conceptualized to reduce malnutrition. However, since the intervention of the NGO into the community, about five years ago, the levels of malnutrition have considerably reduced. Hence the study was re-designed to understand the impact of the supplementary nutrition program on under-nutrition, using ICMR, 1990 guidelines, which recommend ideal anthropometric measurements for specific age.

\section{Acknowledgement:}

The author would like to acknowledge and extent heartfelt gratitude the Foundation of Mother and Child, India, a grass root level NGO, which funded and conducted this study. Also sincere thanks to Dr. Rupal Dalal, the pediatrician, for her vital encouragement and support, Ms. Ratna Thar, for her assistance and understanding for executing the project and Ms. Dorothy Wagle, the Director of the Foundation. Also the author would like to acknowledge and appreciate the support provided by the grass root level team for collection and compilation of the data, which made this research study complete.

\section{References}

Alves, F., Ferraro, A., \& Nascimento, H. (2010), Height and Weight gains in a nutrition rehabilitation day-care service, Public Health Nutrition, 13 (10): 1505-10.

Borrower's Evaluation Report (2006), Implementation Completion Report of World Bank assisted ICDSIII/WCD Project, Government of India (retrieved from wcd.nic.in/PBEvalReport.pdf , on 23rd January 2011).

Caballero, B. \& Maqbool, A. (2003), Nutrition in Pediatrics, International Nutrition, BC Decker Inc: 195-2004.

Chandra, R. \& Kumari, S. (1994), Nutrition and Immunity: An overview, Journal of Nutrition, 124 (8): 1433S1435 S.

Fawzi, W., Herrera, M., Spiegelman, D., El Amin, A. and Nestel, P. (1997). A prospective study of malnutrition in relation to child mortality in the Sudan. American Journal of Clinical Nutrition, 65:1062-1069.

Hasan, I. (2010) A study of prevalence of malnutrition in government school children in field area of Azadnagar Bangalore, (Master's Thesis, Department of Preventive and social medicine, National Institute of Unani Medicine). Retrieved from http://precedings.nature.com/documents/5009/version/1.

Lien, N. Mayer, K. \& Winick, N. (1997), Early Malnutrition and "late" adoption: A study of their effects on development of Korean orphans adopted into American families, The American Journal of Clinical Nutrition, 1734-1739.

Mitra, M., Tiwari, A., Ghosh, R. \& Bharati, P. (2004). Dimensions and causes of child malnutrition: A study of 
preschool children of Raipur, Chhattisgarh, India. Anthropol, 6:247-252.

Mittal, P. (n.d), Child Malnutrition: A policy Failure, MeriNews Bulletin (retrieved from http://www.merinews.com/article/children-malnourishment---a-policy-failure-part ii/15795062.shtml).

NFHS (2006), National Family and Health Survey-3, Vol-1 (retrieved from http://www.nfhsindia.org/volume_1.html).

Pediatric Oncall (n.d), Problems of Malnutrition in India among children less than the age of 5 years (retrieved from http://www.pediatriconcall.com/nutrition/malnutrition.asp).

Pelletier, D., Frongillo, E., \& Habicht, J. (1993), Epidemiologic evidence for potentiating effect of malnutrition on child mortality, American Journal of Public Health, 83(3): 1130-1133.

Shashidhar, H. \& Grigsby, D. (2009), Malnutrition, eMedicine Specialties, Pediatrics (retrieved from http://emedicine.medscape.com/article/985140-overview).

Solomon, A. \& Zemene, T. (2008), Risk factors for severe acute malnutrition in children under the age of five: A case- control study, Ethiopian Journal of Health Development, 22 (1).

UNICEF India (n.d), Reducing under nutrition through community participation (retrieved from http://www.unicef.org/india/nutrition_3889.htm).

World Bank (2009), Undernourished Children: A Call for Reform and Action, India Malnutrition Report (retrieved from http://web.worldbank.org on 23rd January 2011).

WHO (1995), Physical Status: Use and Interpretation of Anthropometry, WHO Expert Committee Technical Report Series no. 854, Geneva, 452. 